\title{
Female sex and cardiovascular disease risk in rural Uganda: a cross-sectional, population-based study
}

Itai M. Magodoro ${ }^{1,2^{*}}$ (D) Maggie Feng ${ }^{2}$, Crystal M. North ${ }^{1,2}$, Dagmar Vořechovská2, John D. Kraemer ${ }^{3}$, Bernard Kakuhikire ${ }^{4}$, David Bangsberg ${ }^{5}$, Alexander C. Tsai ${ }^{1,2}$ and Mark J. Siedner ${ }^{1,2,4,6}$

\begin{abstract}
Background: Sex-based differences in cardiovascular disease (CVD) burden are widely acknowledged, with male sex considered a risk factor in high-income settings. However, these relationships have not been examined in subSaharan Africa (SSA). We aimed to apply the American Heart Association (AHA) ideal cardiovascular health (CVH) tool modified by the addition of C-reactive protein (CRP) to examine potential sex-based differences in the prevalence of CVD risk in rural Uganda.

Methods: In a cross-sectional study nested within a population-wide census, 857 community-living adults completed physical and laboratory-based assessments to calculate individual ideal CVH metrics including an eight category for CRP levels. We summarized sex-specific ideal $\mathrm{CVH}$ indices, fitting ordinal logistic regression models to identify correlates of improving CVH. As secondary outcomes, we assessed subscales of ideal CVH behaviours and factors. Models included inverse probability of sampling weights to determine population-level estimates.

Results: The weighted-population mean age was 39.2 (1.2) years with 52.0 (3.7) \% females. Women had ideal scores in smoking $(80.4 \%$ vs. $68.0 \% ; p<0.001)$ and dietary intake $(26.7 \%$ vs. $16.8 \% ; p=0.037)$ versus men, but the opposite in body mass index (47.3\% vs. $84.4 \% ; p<0.001)$, glycated hemoglobin (87.4\% vs. $95.2 \% ; p=0.001)$, total cholesterol ( $80.2 \%$ vs. $85.0 \% ; p=0.039)$ and CRP (30.8\% vs. $49.7 \% ; p=0.009)$. Overall, significantly more men than women were classified as having optimal cardiovascular health (6-8 metrics attaining ideal level) (39.7\% vs. 29.0\%; $p=0.025)$. In adjusted models, female sex was correlated with lower CVH health factors sub-scales but higher ideal $\mathrm{CVH}$ behaviors.

Conclusions: Contrary to findings in much of the world, female sex in rural SSA is associated with worse ideal CVH profiles, despite women having better indices for ideal CVH behaviors. Future work should assess the potential role of socio-behavioural sex-specific risk factors for ideal CVH in SSA, and better define the downstream consequences of these differences.
\end{abstract}

Keywords: Ideal cardiovascular health, Cardiovascular disease, Population health, Sex differences, Uganda, SubSaharan Africa

\footnotetext{
* Correspondence: Itai_Magodoro@hms.harvard.edu

${ }^{1}$ Harvard Medical School, 125 Shattuck St, Boston, MA 02115, USA

${ }^{2}$ Massachusetts General Hospital, Boston, MA, USA

Full list of author information is available at the end of the article
}

(c) The Author(s). 2019 Open Access This article is distributed under the terms of the Creative Commons Attribution 4.0 International License (http://creativecommons.org/licenses/by/4.0/), which permits unrestricted use, distribution, and reproduction in any medium, provided you give appropriate credit to the original author(s) and the source, provide a link to the Creative Commons license, and indicate if changes were made. The Creative Commons Public Domain Dedication waiver (http://creativecommons.org/publicdomain/zero/1.0/) applies to the data made available in this article, unless otherwise stated. 


\section{Background}

The exacting human cost imposed by cardiovascular diseases (CVDs) in both high and low-income settings has motivated innovative strategies to mitigate their impact. In 2010, the American Heart Association (AHA) [1] introduced the concept of "ideal cardiovascular health (ideal $\mathrm{CVH}$ )" in order to meet the urgent need for preventing cardiovascular morbidity and mortality. Ideal $\mathrm{CVH}$ is based on 7 metrics: smoking status, dietary intake, physical activity, body mass index (BMI), blood pressure (BP), total cholesterol (TC), and fasting blood glucose. When present at ideal levels, increasing frequency of these metrics is mirrored in proportionate decreases in risk of major adverse cardiovascular events (MACE) [2, 3].

Sex is a well-described independent risk factor for CVD $[4,5]$ with male sex considered a risk marker for incident atherosclerotic CVD in high-income settings [6]. This increased risk arises from both biological and sociocultural differences between men and women [7]. Sex as a biological variable underlies physiological variation in vascular function, coagulation, fibrinolysis and energy metabolism, among others [8, 9]. Gender also contributes to CVD risk through differences in social roles, environmental exposures, health seeking behaviors, and access to resources including medical care $[4,10,11]$.

Whether and how these relationships between sex and gender and CVDs apply in sub-Saharan Africa (SSA) is not well known, despite the rapidly increasing burden of CVD in the region [12, 13]. Limited available evidence, however, indicates that women in SSA have a higher age-standardized CVD mortality rate than their male counterparts, and that this is substantially higher than the corresponding rates for both men and women in high-income countries [14]. Thus, an understanding of the role of sex and gender is critically important to curtail the human costs of CVDs and improve CVH in SSA.

To help build the evidence base to support the formulation of data-driven health policies in SSA, we aimed to define the AHA's ideal $\mathrm{CVH}$ construct in a community-based, general population in rural Uganda. We hypothesized that the population distribution of ideal CVH metrics and indices would demonstrate lower rates of ideal $\mathrm{CVH}$ profiles than described elsewhere, and that these would differ between men and women.

\section{Methods}

\section{Study population and setting}

We conducted a cross-sectional study to describe AHA ideal CVH metrics in southwestern Uganda. Participants were community-dwelling adults, residing in Nyakabare Parish, Mbarara District, who attended one of five voluntary health fairs in June 2015. The parish is characterized by a subsistence pastoral-agrarian economy in which both food and water insecurity are common [15]. It is also the location of an ongoing longitudinal study that conducted a census in 2014 and collected data on $98 \%$ of all adults (1814/1851) residing there. Participation in the health fair study was limited to participants in the parent census study. Recruitment was enriched through radio advertisements and announcements at social and religious gatherings. The institutional review boards of Mbarara University of Science and Technology, Uganda, and Partners Healthcare, Boston, approved the protocol, and all study participants gave written informed consent. Consistent with national guidelines, we also obtained clearance for the study from the Ugandan National Council of Science and Technology and from the Research Secretariat in the Office of the President.

\section{Data collection}

Surveys were administered to elicit age; sex; educational attainment; medical history; and active medication use for hypertension, dyslipidemia, heart failure, asthma or diabetes mellitus. We assessed socioeconomic status using household-owned assets and housing characteristics aggregated into an asset wealth index and divided in tertiles [16]. Questionnaires based on the International Physical Activity Questionnaire (IPAQ) [17] and the WHO STEPS instrument [18] were administered to collect data on physical activity, tobacco use, and fruit and vegetable intake. Physical activity was measured as metabolic equivalent of task (MET) in minutes per week [17].

We also measured height, weight, and BP. BP was measured in a seated position using automated sphygmomanometers (Omron HEM 705 LP, Omron Healthcare, Inc., Bannockburn, IL). Venous blood was collected to assess serum lipids, C-reactive protein (CRP), and performed at Epicentre Research Base in Mbarara, Uganda using a Cobas c111 (Roche, Basel, Switzerland) serum chemistry analyser and point-of-care glycated haemoglobin (HbA1c) (Siemens DCA Vantage, Munich, Germany).

\section{AHA cardiovascular health metrics}

We categorized each of the seven $\mathrm{CVH}$ metrics defined by the AHA as poor, intermediate, or ideal based on published guidelines [1]. For our primary analyses, we added CRP as an additional metric, due to its strong correlation with CVD risk in multiple populations [19], allowing for a total of eight categories in our ideal $\mathrm{CVH}$ metrics score (Table 1). We also assigned two AHA sub-categories of ideal $\mathrm{CVH}$, based on AHA recommendations, as: (1) five ideal $\mathrm{CVH}$ factors, which included BP, TC, HbA1c, CRP and BMI; and (2) three ideal CVH 
Table 1 Definitions of American Heart Association Individual Ideal Cardiovascular Health Metrics

\begin{tabular}{|c|c|c|}
\hline \multirow[t]{2}{*}{ Metric } & \multicolumn{2}{|l|}{ Definition } \\
\hline & AHA Criteria & Criteria in present study \\
\hline Total cholesterol (TC) & & No adjustment \\
\hline Ideal & $\begin{array}{l}\mathrm{TC}<200 \mathrm{mg} / \mathrm{dL} \text { without use of any } \\
\text { cholesterol-lowering medication }\end{array}$ & \\
\hline Intermediate & $\begin{array}{l}\mathrm{TC} 200-239 \mathrm{mg} / \mathrm{dL} \text { or } \\
\text { treated to }<200 \mathrm{mg} / \mathrm{dL}\end{array}$ & \\
\hline Poor & $\mathrm{TC} \geq 240 \mathrm{mg} / \mathrm{dL}$ & \\
\hline Blood pressure & & No adjustment \\
\hline Ideal & $\begin{array}{l}\mathrm{BP}<120 /<80 \mathrm{mmHg} \text { without use of } \\
\text { antihypertensive medications }\end{array}$ & \\
\hline Intermediate & $\begin{array}{l}\text { Systolic BP } 120-139 \text { or } \\
\text { diastolic BP } 80-89 \mathrm{mmHg} \text { or } \\
\text { treated to BP }<120 /<80 \mathrm{mmHg}\end{array}$ & \\
\hline Poor & $\mathrm{BP} \geq 140 / \geq 90 \mathrm{mmHg}$ & \\
\hline Fasting plasma glucose & & Glycated hemoglobin \\
\hline Ideal & $<100 \mathrm{mg} / \mathrm{dL}$ & $\begin{array}{l}\mathrm{HbA} 1 \mathrm{c}<5.7 \% \text { and without any } \\
\text { hypoglycemic medication }\end{array}$ \\
\hline Intermediate & $100-125$ mg/dL & $\begin{array}{l}\mathrm{HbA} 1 \mathrm{c} 5.7-6.4 \% \text { or } \\
\text { treated to } \mathrm{HbA} 1 \mathrm{c}<5.7 \%\end{array}$ \\
\hline Poor & $\geq 126 \mathrm{mg} / \mathrm{dl}$ & $\mathrm{HbA} 1 \mathrm{c} \geq 6.5 \%$ \\
\hline Body mass index (BMI) & & No adjustment \\
\hline Ideal & $\mathrm{BMI}<25 \mathrm{~kg} / \mathrm{m}^{2}$ & \\
\hline Intermediate & BMI $25-29.9 \mathrm{~kg} / \mathrm{m}^{2}$ & \\
\hline Poor & $\mathrm{BMI} \geq 30 \mathrm{~kg} / \mathrm{m}^{2}$ & \\
\hline Diet & & No adjustment \\
\hline Ideal & 4-5 components & $\geq 20$ servings/week \\
\hline Intermediate & 2-3 components & \\
\hline Poor & $0-1$ components & $<20$ servings/week \\
\hline Physical activity & & No adjustment \\
\hline Ideal & $\begin{array}{l}\geq 150 \mathrm{~min} / \text { week moderate intensity or } \\
\geq 75 \mathrm{~min} / \text { week vigorous intensity or } \\
\geq 150 \mathrm{~min} / \text { week moderate }+ \text { vigorous }\end{array}$ & $\geq 1500$ METmin/week \\
\hline Intermediate & $\begin{array}{l}\text { 1-149 } \mathrm{min} / \text { week moderate intensity or } \\
1-74 \mathrm{~min} / \text { week vigorous intensity or } \\
1-149 \mathrm{~min} / \text { week moderate }+ \text { vigorous }\end{array}$ & 600-1500METmin/week \\
\hline Poor & None & $<600 \mathrm{METmin} /$ week \\
\hline Smoking & & No adjustment \\
\hline Ideal & Never or quit $>12$ months & $\begin{array}{l}\text { Never having smoked or } \\
\text { quit }>12 \text { months prior }\end{array}$ \\
\hline Intermediate & Former $\leq 12$ months & $\begin{array}{l}\text { Quit within the preceding } \\
1-12 \text { months }\end{array}$ \\
\hline Poor & Current & $\begin{array}{l}\text { Current smoking status or } \\
\text { quit within the preceding } 1 \text { month. }\end{array}$ \\
\hline C-reactive protein (CRP) & None & \\
\hline Ideal & & $\mathrm{CRP}<1.0 \mathrm{mg} / \mathrm{dL}$ \\
\hline Intermediate & & CRP $1-3 \mathrm{mg} / \mathrm{dL}$ \\
\hline Poor & & $\mathrm{CRP} \geq 3 \mathrm{mg} / \mathrm{dL}$ \\
\hline
\end{tabular}


behaviors, which included diet, physical activity, and smoking.

\section{Ideal CVH health factors and health behaviors}

We characterized the $\mathrm{CVH}$ metrics as poor, intermediate, or ideal as indicated in Table 1. In place of plasma fasting glucose in the standard AHA score, we measured $\mathrm{HbA1c}$, and selected the three categories based on international consensus [20] HbA1c thresholds of $<5.7 \%$, $5.7-6.4 \%$ and $\geq 6.5 \%$, respectively, as cut-offs for normal, pre-diabetic, and diabetic states. CRP was categorized as ideal $(<1.0 \mathrm{mg} / \mathrm{dL})$, intermediate $(1-3 \mathrm{mg} / \mathrm{dL})$, and poor $(\geq 3 \mathrm{mg} / \mathrm{dL})$ corresponding to standard definitions of CRP and CVD risk [21]. Complete data were available for only one of the five AHA components used to score the diet metric. We therefore used fruit and vegetable intake to define ideal ( $\geq 20$ servings/week) and non-ideal $(<20$ servings/week) diet as previously described [22]. Physical activity was converted to metabolic equivalents of task (METs) in minutes, and categorized as $\geq 1500$ MET min/week for ideal, 600-1500 MET min/week for intermediate, and $<600 \mathrm{MET}$ min/week for poor physical activity [17].

\section{Data analysis}

We used inverse probability of health fair attendance sampling weights to estimate population-representative descriptive statistics, cardiovascular health metrics, and regression models. To do so, we first estimated the probability of attending the health fair, conditional on participants` characteristics from the community census. This value was calculated by fitting logistic regression models with the entire census dataset, with health fair attendance as the outcome of interest and adjusted for 16 variables predicted to correlate with health fair attendance (See Additional file 1: Methods). This regression assigned a conditional probability weight of health fair attendance for each individual attending the health fair. The inverse of the predicted conditional probabilities of health fair attendance were then applied as stabilized inverse probability of treatment weights (IPTW) using methods described previously by Hernan et al. [23]. We assessed the validity of this method by comparing population characteristics as estimated by our IPTW models with variables in the census that were not included in the IPTW model (Additional file 1: Table S3).

We next summarized the weighted population dataset, applying stabilized IPTW weights, to obtain populationlevel characteristics and proportions assigned to each cardiovascular health index. Continuous variables were described by means and standard errors (SEs), and comparisons between groups were made using $t$-tests or corresponding nonparametric tests after assessing distributional properties. Categorical variables were described by percentages and compared by chi-squared tests.

Our primary outcome of interest was AHA ideal CVH metric score, which was categorized as an integer value ranging from 0 to 8 where participants received one point per criterion met for ideal health. As secondary outcomes of interest, we assessed ideal $\mathrm{CVH}$ behaviors as a score of $0-3$ and ideal $\mathrm{CVH}$ factors as a score of 0 5. Our primary exposure of interest was sex. Secondary exposures of interest were age, categorized as 18-39; $40-59$; and $\geq 60$ years, wealth, categorized as tertiles of the Filmer-Pritchett asset index, and educational attainment. "Education was categorized as none", "some primary education", "completed primary education" and "post-primary education".

We examined the distribution of each of the $\mathrm{CVH}$ metrics according to $\mathrm{CVH}$ status (poor, intermediate and ideal) stratified by sex and age. The numbers of health factors and health behaviors at the ideal level were also examined and graphically depicted by age and sex strata. Finally, we then fit univariable and multivariable ordinal logistic regression models to estimate adjusted associations between sex and indices of ideal cardiovascular health, ideal health behaviors and ideal health factors; and estimated the mean predicted probabilities of ideal $\mathrm{CVH}$ behaviors and factors by age and sex using post-estimation margins [24]. All statistical analyses were performed using Stata software (version 14.0, StataCorp, College Station, TX) with a two-sided $P$-value $<0.05$ considered statistically significant.

\section{Results}

\section{Demographic characteristics}

A total of 857 individuals attended a health fair out of 1814 (47\%) cohort participants. Analyses were confined to 756 (42\%) participants with complete data to calculate all 7 AHA CVH metrics plus CRP. Compared to non-attendees, health fair attendees were older $(p<$ $0.001)$, more likely to be female $(\mathrm{p}<0.001)$, with less formal educational attainment $(\mathrm{p}<0.001)$. Notably, attendees were twice as likely as non-attendees to report very bad or bad health $(1.4 \%$ vs. 0.7 , and $26.5 \%$ vs. $13.1 \%$, respectively, $\mathrm{p}<0.001$ ) (Additional file 1 : Table S4). There were no significant differences in cardiovascular risk characteristics between health fair attendees who were included or excluded from the analysis due to missing data (Additional file 1: Table S5).

The weighted study population mean age was 39.2 years (1.2), (Table 2). The population was $52.0 \%$ female, and 4.1 and $3.3 \%$, respectively, had a history of heart failure or stroke. Compared to men, women were significantly older (41.5 vs. 36.8 years; $p=0.016)$, were less likely to have formal education (none: $20.1 \%$ vs. $5.2 \%$ ), were more likely to be poor ( $44.2 \%$ vs. $29.1 \%)$, and had a 
Table 2 Baseline characteristics of weighted population

\begin{tabular}{|c|c|c|c|c|}
\hline & \multicolumn{4}{|c|}{ Weighted population estimate, mean (SE) or proportion (\%) (SE) } \\
\hline & Female & Male & $P$ value ${ }^{a}$ & Total \\
\hline $\operatorname{Sex}(\%)$ & $52.0(3.7)$ & $48.0(3.7)$ & 0.656 & - \\
\hline Age, mean (years) & $41.5(1.1)$ & $36.8(1.7)$ & 0.016 & $39.2(1.0)$ \\
\hline \multicolumn{5}{|l|}{ Age group (years) (\%) } \\
\hline $16-39$ & $54.1(3.0)$ & $66.0(4.3)$ & & $59.9(2.8)$ \\
\hline $40-64$ & $30.6(2.6)$ & $23.1(3.3)$ & & $26.9(2.2)$ \\
\hline$\geq 65$ & $15.3(1.9)$ & $10.9(2.0)$ & 0.042 & $13.2(1.4)$ \\
\hline $\mathrm{BMI}\left(\mathrm{kg} / \mathrm{m}^{2}\right)$ & $26.0(0.3)$ & $22.4(0.2)$ & $<0.001$ & $24.3(0.2)$ \\
\hline \multicolumn{5}{|l|}{ Formal educational attainment (\%) } \\
\hline None & $20.1(2.0)$ & $5.2(1.3)$ & & $12.8(1.3)$ \\
\hline Some primary education & $30.4(2.5)$ & $20.8(3.1)$ & & $25.7(2.1)$ \\
\hline Completed primary education & $21.8(2.3)$ & $24.4(4.2)$ & & $23.1(2.3)$ \\
\hline Post-primary education & $27.7(3.4)$ & $49.5(5.7)$ & $<0.001$ & $38.4(3.6)$ \\
\hline \multicolumn{5}{|l|}{ Filmer-Pritchett asset index (\%) } \\
\hline Poor & $44.2(2.9)$ & $29.1(4.2)$ & & $36.7(2.7)$ \\
\hline Middle & $18.2(2.0)$ & $25.6(6.1)$ & & $21.8(3.2)$ \\
\hline Rich & $37.6(3.1)$ & $45.3(5.7)$ & 0.047 & $41.5(3.2)$ \\
\hline History of heart failure (\%) & $6.3(1.1)$ & $1.8(0.1)$ & 0.012 & $4.1(0.7)$ \\
\hline History of stroke (\%) & $1.8(0.5)$ & $4.8(2.3)$ & 0.078 & $3.3(1.2)$ \\
\hline Current hypertension $(\%)^{b}$ & $12.3(1.8)$ & $8.8(1.8)$ & 0.204 & $10.6(1.4)$ \\
\hline Systolic BP (mmHg) & $123.7(1.4)$ & $124.5(1.4)$ & 0.564 & $124.0(1.0)$ \\
\hline Diastolic BP (mmHg) & $80.1(0.8)$ & $76.7(1.3)$ & 0.024 & $78.5(0.8)$ \\
\hline Current diabetes mellitus $^{c}$ & $2.2(0.7)$ & $1.6(0.7)$ & 0.546 & $2.0(0.5)$ \\
\hline $\mathrm{HbA1c}(\%)$ & $5.3(0.04)$ & $5.1(0.03)$ & $>0.001$ & $5.2(0.03)$ \\
\hline Total cholesterol (mg/dL) & $167.0(2.4)$ & $155.7(5.2)$ & 0.049 & $161.5(2.8)$ \\
\hline Current use of chronic medication (\%) & $6.2(1.2)$ & $2.9(0.1)$ & 0.037 & $4.6(0.8)$ \\
\hline
\end{tabular}

${ }^{\mathrm{a} B o l d f a c e ~ i n d i c a t e s ~ s t a t i s t i c a l ~ s i g n i f i c a n c e ~}(p<0.05)$

${ }^{\mathrm{b}}$ Self-reported hypertension and/or blood pressure $\geq 140 / 90 \mathrm{mmHg}$ at screening

'Self-reported diabetes mellitus and/or $\mathrm{HbA} 1 \mathrm{c} \geq 6.5 \%$

higher BMI (mean BMI 26.0 vs. $22.4 \mathrm{~kg} / \mathrm{m} 2 ; p<0.001$ ). Three times as many women as men self-reported heart failure history (6.3\% vs. 1.8\%: $p=0.012)$.

\section{Cardiovascular health indices}

The distribution of individual CVH metrics in the total population, and stratified by age and sex, are shown in Additional file 1: Table S1 and Fig. 1. Figures 2 and 3 depict the distribution of the number of ideal components of cardiovascular health, behaviors and factors by sex. Overall, only $3.2 \%$ of the weighted population had all 7 AHA metrics and CRP at ideal CVH levels. Though more women than men had all 8 metrics (CRP plus 7 AHA) at the ideal level ( $4.4 \%$ vs. $1.8 \% ; p=0.018)$, men had a higher number of metrics at ideal level out of 8 (5.1 vs. $4.7 ; p=0.010$ ) and higher proportion with at least 6 ideal $\mathrm{CVH}$ metrics $(39.7 \%$ vs. $29.0 \% ; p=0.025)$ (Additional file 1: Table S2).
Men and women tended to have similar levels of ideal $\mathrm{CVH}$ categories for $\mathrm{BP}$ and physical activity (Fig. 1). However, men had a higher frequency of BMI, TC, HbA1c and CRP achieving ideal health status than the women. Overall, men had better $\mathrm{CVH}$ factor profiles (5 out of 5 metrics at ideal level) than women $(16.3 \%$ vs. 9.4\%; $p<0.001)$. However, women had the more favorable CVH behaviors profile ( 3 out of 3 metrics at ideal level) ( $8.8 \%$ vs. $20.4 \%$; $p=0.027)$ (Figs. 2 and 3$)$.

In univariable models, female sex was associated with worsening CVH status (OR 0.59; 95\% CI: 0.40-0.87; $p=$ 0.008) (Table 3). After adjusting for age, asset wealth and education, female sex remained correlated with worse $\mathrm{CVH}$ metrics, although this did not achieve statistical significance (adjusted OR 0.70; 95\%CI: 0.47-1.03). Interestingly, women were more likely than men to be classified into higher categories of ideal $\mathrm{CVH}$ behaviors (adjusted OR 2.87; 95\% CI: 1.72-4.78; $p<0.001$ ), but less 


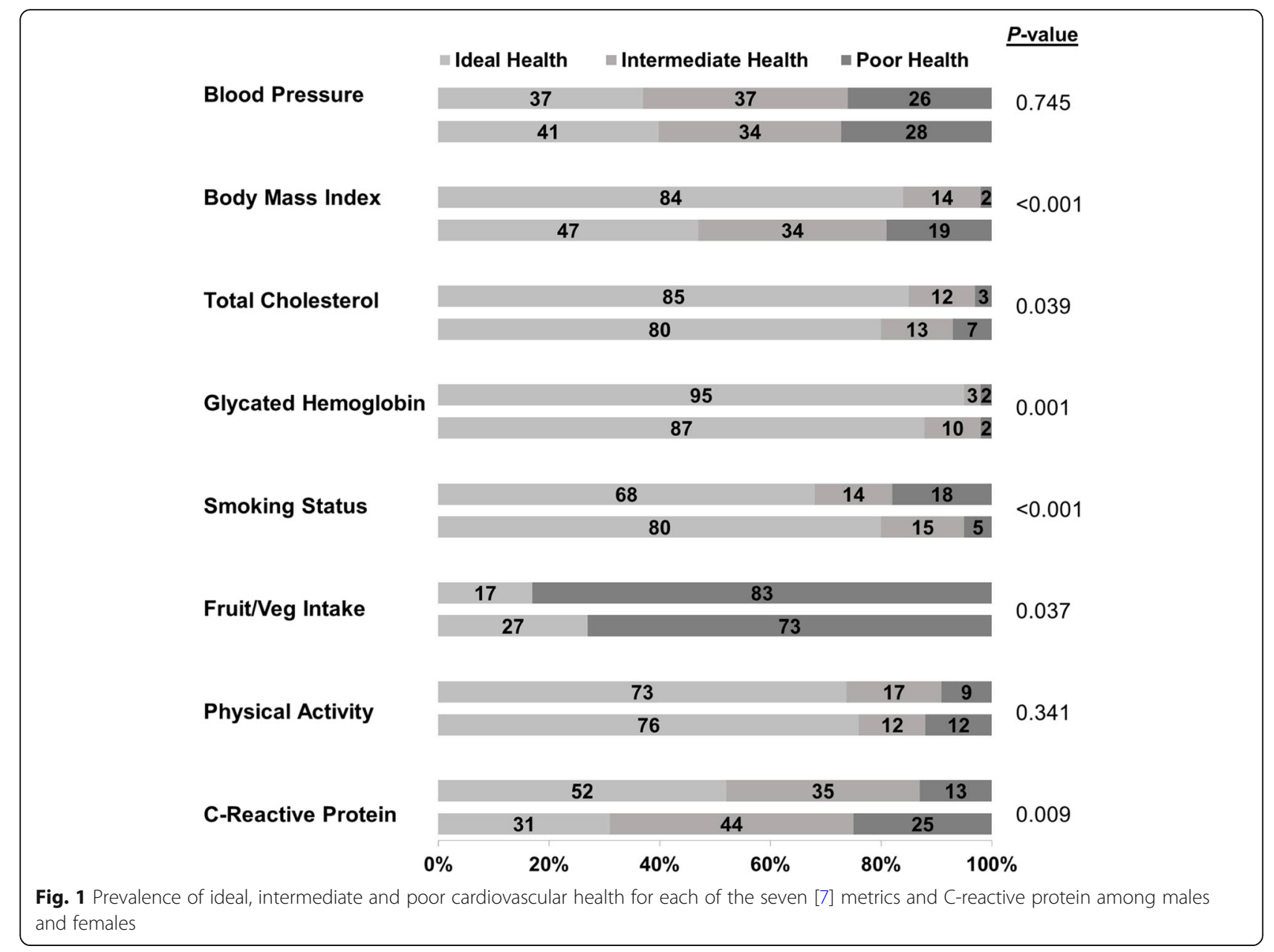

likely to be classified into higher categories of ideal $\mathrm{CVH}$ factors (adjusted OR 0.32; 95\% CI: 0.21-0.49; p < 0.001) (Tables 4 and 5). In all models, increasing age was significantly associated with having fewer $\mathrm{CVH}$ metrics and factors. In both adjusted and unadjusted models, having some formal education, relative to no education, was positively correlated with ideal $\mathrm{CVH}$ behaviors. In contrast, relative household wealth was negatively associated with ideal $\mathrm{CVH}$ metrics and ideal health factors. Compared to the poorest quartile of asset ownership, increasing wealth predicted worsening $\mathrm{CVH}$ metrics and health factors. However, we found no apparent relationship between relative household wealth and health behaviors. The mean adjusted probabilities of having all 3 behaviors at the ideal $\mathrm{CVH}$ level, if age, wealth and educational attainment were equal to mean for all participants, were $18.0 \%$ (95\% CI: $12.8-23.2 \%$ ) for women and $7.1 \%$ (95\% CI: 3.9-10.4) for men. The corresponding adjusted probabilities of having all 5 factors attaining ideal CVH level were 5.8\% (95\% CI: 3.18.6) for women and $16.0 \%$ (95\% CI: 9.0-23.0) for men (Tables 6 and 7).

\section{Discussion}

In this cross-sectional, population-based study in rural Uganda, we found significant sex-based differences in CVH metrics. Based on a modified definition of AHA ideal CVH with 8 metrics, significantly more men than women were classified as having optimum $\mathrm{CVH}(6-8$ metrics attaining ideal level) (39.7\% vs. $29.0 \% ; p=0.025)$, while 3 times as many women as men had poor $\mathrm{CVH}$ $(0-2$ metrics attaining ideal level $)(7.8 \%$ vs. $2.9 \% ; \mathrm{p}=$ 0.025). Additionally, women had significantly worse $\mathrm{CVH}$ factor profiles despite having significantly increased $\mathrm{CVH}$ behavior profiles. These relationships remained consistent after adjustment for age, household wealth and educational attainment.

The sex differences in ideal $\mathrm{CVH}$ were unexpected, and contrary to what has been reported in high-income areas. For example, in the Heart SCORE study [25], reporting on ideal $\mathrm{CVH}$ among community-living adults (mean age 59 years) of mixed ethnicity/race in the USA, women had better $\mathrm{CVH}$ factor profiles than men but similar $\mathrm{CVH}$ behavior profiles. Similarly, in an urban center in Northern China [26], the proportion of women 


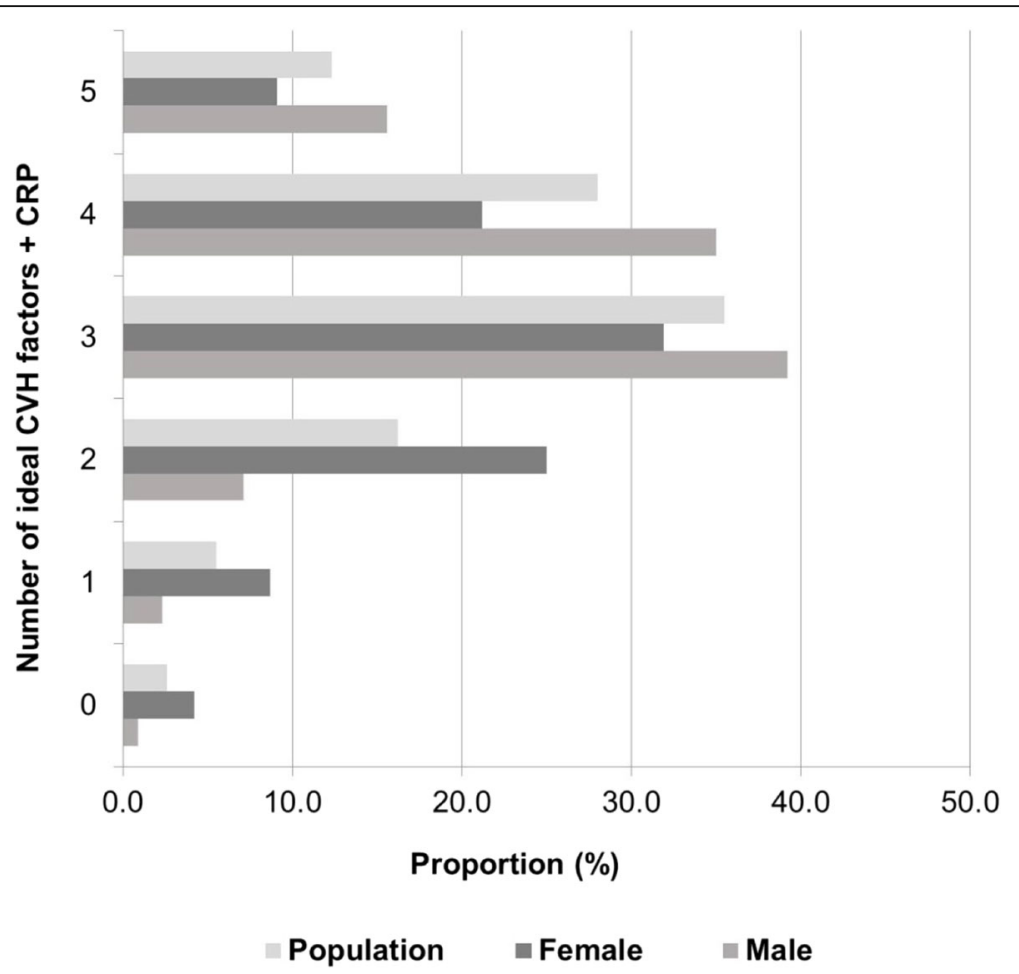

Fig. 2 Weighted proportion of subjects with different numbers of ideal cardiovascular health factors in the overall population according to sex

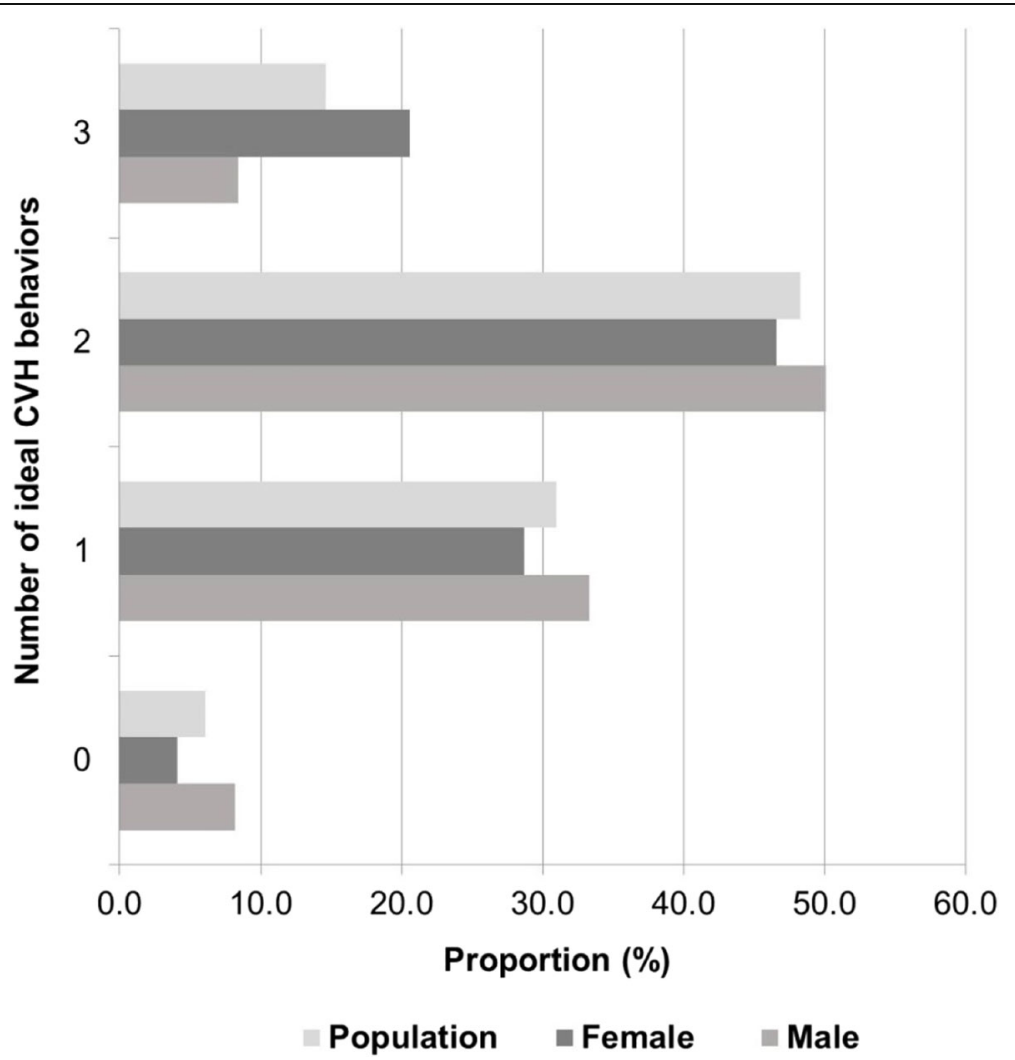

Fig. 3 Weighted proportion of subjects with different numbers of ideal cardiovascular health behaviors in the overall population according to sex 
Table 3 Association between ideal cardiovascular health metrics and demographic and socio-economic variables - ordered logistic regression

\begin{tabular}{|c|c|c|c|c|c|c|}
\hline & \multicolumn{6}{|c|}{ Ideal CVH metrics } \\
\hline & \multicolumn{3}{|c|}{ Univariate } & \multicolumn{3}{|c|}{ Multivariable } \\
\hline & $\overline{\mathrm{OR}}$ & $95 \% \mathrm{Cl}$ & $P$ value $^{a}$ & $\overline{\mathrm{OR}}$ & $95 \% \mathrm{Cl}$ & $P$ value $^{a}$ \\
\hline \multicolumn{7}{|l|}{ Sex } \\
\hline Male & 1.00 & & & 1.0 & & \\
\hline Female & 0.59 & $0.40-0.87$ & 0.008 & 0.70 & $0.47-1.03$ & 0.072 \\
\hline \multicolumn{7}{|l|}{ Age group (years) } \\
\hline $16-39$ & 1.00 & & & 1.00 & & \\
\hline $40-60$ & 0.35 & $0.23-0.54$ & $<0.001$ & 0.36 & $0.24-0.55$ & $<0.001$ \\
\hline$\geq 60$ & 0.10 & $0.06-0.16$ & $<0.001$ & 0.10 & $0.06-0.18$ & $<0.001$ \\
\hline \multicolumn{7}{|c|}{ Filmer-Pritchett asset index } \\
\hline Poor & 1.00 & & & 1.00 & & \\
\hline Middle & 0.77 & $0.54-1.11$ & 0.160 & 0.58 & $0.34-0.94$ & 0.028 \\
\hline Rich & 0.57 & $0.34-0.94$ & 0.027 & 0.38 & $0.22-0.62$ & $<0.001$ \\
\hline \multicolumn{7}{|c|}{ Highest educational attainment (\%) } \\
\hline None & 1.0 & & & 1.0 & & \\
\hline Some primary & 2.17 & $1.40-3.37$ & 0.001 & 1.39 & $0.84-2.30$ & 0.195 \\
\hline Completed primary & 2.95 & $1.81-4.80$ & $<0.001$ & 1.51 & $0.83-2.73$ & 0.177 \\
\hline Post-primary & 3.40 & $1.97-5.88$ & $<0.001$ & 1.99 & $1.08-3.66$ & 0.027 \\
\hline
\end{tabular}

a Boldface indicates statistical significance $(p<0.05)$

Table 4 Association between ideal cardiovascular health factors and demographic and socio-economic variables - ordered logistic regression

\begin{tabular}{|c|c|c|c|c|c|c|}
\hline & \multicolumn{6}{|c|}{ Ideal CVH Factors } \\
\hline & \multicolumn{3}{|c|}{ Univariate } & \multicolumn{3}{|c|}{ Multivariable } \\
\hline & $\overline{O R}$ & $95 \% \mathrm{Cl}$ & $P$ value $^{a}$ & $\overline{\mathrm{OR}}$ & $95 \% \mathrm{Cl}$ & $P$ value $^{c}$ \\
\hline \multicolumn{7}{|l|}{ Sex } \\
\hline Male & 1.00 & & & 1.0 & & \\
\hline Female & 0.34 & $0.23-0.52$ & $<0.001$ & 0.32 & $0.21-0.49$ & $<0.001$ \\
\hline \multicolumn{7}{|l|}{ Age group (years) } \\
\hline $16-39$ & 1.00 & & & 1.00 & & \\
\hline $40-60$ & 0.42 & $0.28-0.63$ & $<0.001$ & 0.41 & $0.27-0.62$ & $<0.001$ \\
\hline$\geq 60$ & 0.25 & $0.15-0.40$ & $<0.001$ & 0.21 & $0.13-0.35$ & $<0.001$ \\
\hline \multicolumn{7}{|c|}{ Filmer-Pritchett asset index } \\
\hline Poor & 1.00 & & & 1.00 & & \\
\hline Middle & 0.61 & $0.41-0.91$ & 0.014 & 0.47 & $0.26-0.86$ & 0.015 \\
\hline Rich & 0.44 & $0.26-0.75$ & 0.003 & 0.31 & $0.18-0.53$ & $<0.001$ \\
\hline \multicolumn{7}{|c|}{ Highest educational attainment (\%) } \\
\hline None & 1.0 & & & 1.0 & & \\
\hline Some primary & 1.46 & $0.96-2.22$ & 0.075 & 1.01 & $0.64-1.61$ & 0.958 \\
\hline Completed primary & 2.08 & $1.25-3.46$ & 0.003 & 1.15 & $0.67-1.97$ & 0.614 \\
\hline Post-primary & 1.84 & $1.08-3.12$ & 0.024 & 1.08 & $0.56-2.08$ & 0.826 \\
\hline
\end{tabular}

${ }^{a}$ Boldface indicates statistical significance $\left({ }^{*} p<0.05\right)$ 
Table 5 Association between ideal cardiovascular health behaviors and demographic and socio-economic variables - ordered logistic regression

\begin{tabular}{|c|c|c|c|c|c|c|}
\hline \multirow[t]{3}{*}{ Characteristic } & \multicolumn{6}{|c|}{ Ideal CVH Behaviors } \\
\hline & \multicolumn{3}{|c|}{ Univariate } & \multicolumn{3}{|c|}{ Multivariable } \\
\hline & $\overline{\mathrm{OR}}$ & $95 \% \mathrm{Cl}$ & $P$ value $^{a}$ & $\overline{\mathrm{OR}}$ & $95 \% \mathrm{Cl}$ & $P$ value $^{a}$ \\
\hline \multicolumn{7}{|l|}{ Sex } \\
\hline Male & 1.00 & & & 1.0 & & \\
\hline Female & 1.76 & $1.14-2.72$ & $<0.001$ & 2.87 & $1.72-4.78$ & $<0.001$ \\
\hline \multicolumn{7}{|l|}{ Age group (years) } \\
\hline $16-39$ & 1.00 & & & 1.00 & & \\
\hline $40-60$ & 0.57 & $0.37-0.88$ & 0.011 & 0.56 & $0.36-0.88$ & 0.011 \\
\hline$\geq 60$ & 0.12 & $0.07-0.21$ & $<0.001$ & 0.15 & $0.08-0.27$ & $<0.001$ \\
\hline \multicolumn{7}{|c|}{ Filmer-Pritchett asset index } \\
\hline Poor & 1.00 & & & 1.00 & & \\
\hline Middle & 1.14 & $0.71-1.82$ & 0.585 & 1.04 & $0.66-1.64$ & 0.858 \\
\hline Rich & 1.05 & $0.64-1.71$ & 0.860 & 0.86 & $0.52-1.41$ & 0.557 \\
\hline \multicolumn{7}{|c|}{ Highest educational attainment (\%) } \\
\hline None & 1.0 & & & 1.0 & & \\
\hline Some primary & 2.60 & $1.50-4.48$ & 0.001 & 1.95 & $1.11-3.43$ & 0.020 \\
\hline Completed primary & 2.92 & $1.57-5.42$ & 0.001 & 1.95 & $0.97-3.92$ & 0.059 \\
\hline Post-primary & 3.98 & $2.14-7.39$ & $<0.001$ & 3.38 & $1.67-6.84$ & 0.001 \\
\hline
\end{tabular}

${ }^{a}$ Boldface indicates statistical significance $\left({ }^{*} p<0.05\right)$

Table 6 Adjusted probability of ideal cardiovascular health metrics by demographic and socio-economic characteristics

\begin{tabular}{|c|c|c|c|c|c|}
\hline & \multicolumn{5}{|c|}{ Adjusted predicted probability, \% (95\% Cl) } \\
\hline & \multicolumn{5}{|c|}{ Number of ideal $\mathrm{CVH}$ factors } \\
\hline & $\leq 1$ & 2 & 3 & 4 & 5 \\
\hline Mean overall probability & $6.0(4.3-7.5)$ & $14.9(12.1-17.8)$ & $41.4(34.1-48.7)$ & $28.3(22.0-34.5)$ & $9.4(5.6-13.3)$ \\
\hline \multicolumn{6}{|l|}{ Sex } \\
\hline Female & $9.7(6.7-12.7)$ & $21.2(16.4-26.0)$ & $42.4(35.9-49.0)$ & $20.8(14.7-26.9)$ & $5.8(3.1-8.6)$ \\
\hline Male & $3.4(2.2-4.6)$ & $9.3(6.8-11.9)$ & $34.6(26.1-43.0)$ & $36.7(29.3-44.1)$ & $16.0(9.0-23.0)$ \\
\hline \multicolumn{6}{|l|}{ Age group (years) } \\
\hline $16-39$ & $3.8(2.5-5.0)$ & $10.3(7.8-12.8)$ & $37.3(28.9-45.6)$ & $35.3(27.8-42.9)$ & $14.5(8.1-20.9)$ \\
\hline $40-60$ & $8.6(5.7-11.5)$ & $19.5(14.3-24.7)$ & $42.5(35.8-49.3)$ & $22.7(16.7-28.8)$ & $6.6(3.7-9.6)$ \\
\hline$\geq 60$ & $15.7(9.1-22.3)$ & $28.0(21.4-34.5)$ & $39.0(32.1-46.0)$ & $13.9(7.8-19.9)$ & $3.5(1.4-5.6)$ \\
\hline \multicolumn{6}{|l|}{ Filmer-Pritchett asset index } \\
\hline Poor & $3.1(1.9-4.3)$ & $8.6(5.9-11.3)$ & $33.3(25.9-40.6)$ & $37.7(30.4-45.0)$ & $17.3(10.6-23.9)$ \\
\hline Middle & $6.4(2.8-9.9)$ & $15.7(9.8-21.5)$ & $41.5(32.7-50.2)$ & $27.6(16.2-38.9)$ & $8.9(3.6-14.3)$ \\
\hline Rich & $9.4(5.9-12.8)$ & $20.7(14.8-26.6)$ & $42.5(35.9-49.1)$ & $21.3(14.5-28.2)$ & $6.1(2.5-9.6)$ \\
\hline \multicolumn{6}{|c|}{ Highest educational attainment (\%) } \\
\hline None & $6.3(3.6-9.1)$ & $15.6(10.2-21.0)$ & $41.4(33.8-49.1)$ & $27.6(19.1-36.1)$ & $9.0(4.1-13.8)$ \\
\hline Some primary & $6.2(4.0-8.3)$ & $15.3(11.4-19.2)$ & $41.2(34.4-48.1)$ & $28.1(21.8-34.4)$ & $9.2(5.6-12.8)$ \\
\hline Completed primary & $5.3(3.2-7.5)$ & $13.7(9.1-18.4)$ & $40.1(33.32-47.0$ & $30.3(23.2-37.2)$ & $10.5(5.9-15.1)$ \\
\hline Post-primary & $5.7(3.0-8.3)$ & $14.4(9.5-19.2)$ & $40.6(31.5-49.8)$ & $29.4(19.6-39.1)$ & $10.0(3.8-16.1)$ \\
\hline
\end{tabular}


Table 7 Adjusted probability of ideal cardiovascular health behaviors by demographic and socio-economic characteristics

\begin{tabular}{|c|c|c|c|c|}
\hline & \multicolumn{4}{|c|}{ Adjusted predicted probability, \% (95\% Cl) } \\
\hline & \multicolumn{4}{|c|}{ Number of ideal cardiovascular health behaviors } \\
\hline & 0 & 1 & 2 & 3 \\
\hline Mean overall probability & $4.3(2.7-5.8)$ & $31.6(25.3-37.9)$ & $52.7(45.3-60.1)$ & $11.4(8.0-14.9)$ \\
\hline \multicolumn{5}{|l|}{ Sex } \\
\hline Female & $2.6(1.4-3.9)$ & $42.3(34.2-50.4)$ & $56.5(48.7-64.3)$ & $18.0(12.8-23.2)$ \\
\hline Male & $7.2(4.4-10.0)$ & $22.8(15.7-30.0)$ & $43.4(35.3-51.4)$ & $7.1(3.9-10.4)$ \\
\hline \multicolumn{5}{|l|}{ Age group (years) } \\
\hline $16-39$ & $2.9(1.6-4.2)$ & $24.6(17.3-31.9)$ & $56.0(48.1-63.8)$ & $16.5(11.3-21.7)$ \\
\hline $40-60$ & $5.21(2.9-7.2)$ & $35.2(28.2-42.3)$ & $49.7(42.2-57.1)$ & $10.0(6.0-14.0)$ \\
\hline$\geq 60$ & $17.1(9.6-24.5)$ & $55.1(47.7-62.5)$ & $25.0(15.4-34.6)$ & $2.8(1.0-4.6)$ \\
\hline \multicolumn{5}{|l|}{ Filmer-Pritchett asset index } \\
\hline Poor & $4.1(2.2-6.0)$ & $31.1(23.5-38.8)$ & $52.6(44.8-60.4)$ & $12.1(7.3-16.9)$ \\
\hline Middle & $4.0(2.2-5.8)$ & $30.4(23.5-37.2)$ & $53.1(45.1-61.1)$ & $12.6(8.7-16.4)$ \\
\hline Rich & $4.8(2.7-6.8)$ & $34.0(24.4-43.6)$ & $50.6(41.5-59.7)$ & $10.6(6.1-15.0)$ \\
\hline \multicolumn{5}{|c|}{ Highest educational attainment (\%) } \\
\hline None & $9.2(4.3-14.1)$ & $46.9(36.7-57.1)$ & $38.3(27.2-49.4)$ & $5.5(2.1-8.9)$ \\
\hline Some primary & $4.9(2.9-7.0)$ & $34.6(27.8-41.4)$ & $50.1(42.7-57.5)$ & $10.3(6.3-14.3)$ \\
\hline Completed primary & $4.9(2.5-7.4)$ & $34.6(25.4-43.9)$ & $50.1(41.4-58.9)$ & $10.3(5.4-15.2)$ \\
\hline Post-primary & $2.9(1.4-4.4)$ & $24.6(15.3-33.8)$ & $56.0(47.7-64.2)$ & $16.6(10.3-22.8)$ \\
\hline
\end{tabular}

with 6-7 ideal CVH metrics was 11-fold higher than that of their male counterparts $(3.42 \%$ vs. $0.31 \%$; $p<$ $0.001)$. A similar trend has also been reported in rural China [27]. Nonetheless, an increased risk for cardiovascular deaths among women versus men in SSA consistent with our results was also demonstrated in a study by Mensah et. al., [14]. If this data is corroborated with prospective data including outcomes, it would argue for a reconsideration of male sex as a primary risk factor for MACE in the region.

The sex-based differences in ideal $\mathrm{CVH}$ we noted were driven partially by elevated levels of CRP, which were present in most women. Systemic inflammation is an important pathophysiological mechanism underlying CVD, and increased CRP levels are independently predictive of MACE in western populations [28]. Systemic inflammation has complex associations with the AHA metrics. Smoking, diet and physical activity, for example, are causally related to inflammation [29-31]. However, the fact that women in our study and others in Uganda had better health behaviors and worse inflammatory profiles than the men, suggests the presence of an alternative mechanism for increased inflammation in this population.

One possible cause for these differences in systemic inflammation may be chronic exposure to biomass fuel combustion. Wood and other solid biomass fuels are the main energy sources for cooking in many households in SSA. Cooking in Ugandan villages is generally done by girls and women, and often in poorly ventilated kitchens [32]. Thus exposure to polluted indoor air begins in early life for many women. Biomass gases cause systemic inflammation and oxidative stress, which may be the mechanistic pathways involved in CVD development [33-35]. One study in rural India recently reported greater prevalence of hypertension among relatively young, never-smoking housewives who cooked exclusively with biomass compared to age-, sex- and community-matched peers using alternative energy sources [36]. This hypothesis remains to be tested in SSA, where $81 \%$ of households use biomass fuels as their primary energy source [37].

In addition to worse ideal $\mathrm{CVH}$ profiles among women, our findings also indicate a relatively high prevalence of ideal $\mathrm{CVH}$ in rural Uganda compared to other populations. We estimated that approximately 1 in 5 individuals (22.3\%) of our study population had at least 6 AHA standard metrics at ideal level, which is at least twice as high as the prevalence in other comparably young populations. For example, Ogunmoroti et. al. (2015) [38], reported a prevalence of $12 \%$ for ideal $\mathrm{CVH}$ ( $\geq 6$ ideal metrics) in a US-based population with mean age 43 years. The prevalence was much lower at $0.3 \%$ in an Iranian population with a mean age 41 years [39].

We also found an unexpected relationship between household wealth and CVD risk profiles. The protective effect of increasing economic wellbeing on CVD risk is 
well established in many studies [40, 41]. In contrast, we found that increasing household wealth was correlated with worsening ideal $\mathrm{CVH}$ health factors. This finding warrants further exploration $[42,43]$.

\section{Strengths and limitations}

There are a number of limitations to our study. The absence of longitudinal data on ideal $\mathrm{CVH}$ metrics in our study population prevents us from estimating temporal trends in CVD risk, and confirming whether CVD risk factors predict CVH morbidity or mortality. The lack of population-based cardiovascular outcomes data in Uganda largely precludes such estimation of the clinical and population health implications of our findings. As a cross-sectional study, we are further limited to correlational inferences between ideal $\mathrm{CVH}$ metrics, sex/gender and social determinants. Finally, our study used definitions of dietary intake and glucose metabolism that differed than those recommended by the AHA. This should be considered when making direct comparisons with other studies of ideal CVH metrics.

Our study also had important strengths. As a relatively large population-based study, with participants drawn from a complete census, we were able to make population level estimates and generalize our results to similar areas of rural Uganda. Differential participation in the health fairs was accounted for with the use of IPTW-adjusted models to derive population-level estimates. We were also able to include both unique biomedical factors, such as CRP, and social determinants of health, such as wealth, education, and sex to contextualize our findings beyond basic CVD risk estimation.

\section{Conclusions}

In this analysis, we present one of the first reports of AHA ideal CVH metrics from SSA. We demonstrated that women had worse $\mathrm{CVH}$ factors, despite having better $\mathrm{CVH}$ behaviors than men, and that age, wealth, and education all contribute to CVD risk in this setting. Our findings highlight additional areas to be prioritized for further study, including the downstream repercussions of these relationships between sex and ideal CVH profiles, and the potential role of behavioral exposures, such as biomass fuel, as sex-specific CVD risk factors.

\section{Additional file}

Additional file 1: Table 1: Distribution of individual cardiovascular health metrics for the weighted population. Table 2: Prevalence of ideal cardiovascular health metrics according to age and sex. Table 3: Comparison of population estimates based on weightings from inverse probability of health fair attendance models versus true population statistics. Table 4: Characteristics of Health Fair Attendees versus Non-attendees. Table 5: Comparison of characteristics of participants with and without complete AHA metrics data. Methods: Description of variables used in the inverse probability of treatment weights (IPTW). (DOCX $33 \mathrm{~kb}$ )

\section{Abbreviations}

AHA: American Heart Association; BMI: Body mass index; CRP: C - reactive protein; CVD: Cardiovascular disease; $\mathrm{CVH}$ : Cardiovascular health; IPAQ: International physical activity questionnaire; IPTW: Inverse probability of treatment weights; MACE: Major adverse cardiovascular events; MET: Metabolic equivalent of task; SSA: Sub-Saharan Africa; STEPS: STEPwise approach to surveillance; WHO: World Health Organization

\section{Acknowledgements}

Not applicable.

\section{Funding}

Dr. Magodoro receives scholarship support from Harvard Medical School. Dr. Siedner receives support from the National Institute of Health (K23 MH099916) and the Harvard Center for AIDS Research (P30 AI060354). The funding agencies played no role in the conduct of the research or preparation of the manuscript.

\section{Availability of data and materials}

The datasets generated and/or analysed during the current study are not publicly available as the authors do not have permission to share the data.

\section{Authors' contributions}

IMM, MF, CMN, BK, DRB, and ACT conceived the idea and designed the study. IMM and MJS conducted statistical analyses. IMM drafted the initial manuscript. MF, DV, BK, CMN, DRB, ACT, and MJS collected the data. All authors edited and approved the final manuscript.

\section{Ethics approval and consent to participate}

The institutional review boards of Mbarara University of Science and Technology, Uganda, and Partners Healthcare, Boston, approved the protocol, and all study participants gave written informed consent. Consistent with national guidelines, we also obtained clearance for the study from the Ugandan National Council of Science and Technology and from the Research Secretariat in the Office of the President.

\section{Consent for publication}

Not applicable.

\section{Competing interests}

All authors declare that no competing financial interests exist with any organizations that might have an interest in the submitted work or any other relationships or activities that could appear to have influenced the submitted work.

\section{Publisher's Note}

Springer Nature remains neutral with regard to jurisdictional claims in published maps and institutional affiliations.

\section{Author details \\ ${ }^{1}$ Harvard Medical School, 125 Shattuck St, Boston, MA 02115, USA. ${ }^{2}$ Massachusetts General Hospital, Boston, MA, USA. ${ }^{3}$ Department of Health Systems Administration, Georgetown University, Washington, DC, USA. ${ }^{4}$ Mbarara University of Science \& Technology, Mbarara, Uganda. ${ }^{5}$ Oregon Health \& Science University-Portland State University School of Public Health, Portland, Oregon, USA. ${ }^{6}$ Africa Health Research Institute, Durban, KwaZulu-Natal, South Africa.}

Received: 9 October 2018 Accepted: 9 April 2019

Published online: 25 April 2019

\section{References}

1. Lloyd-Jones DM, Hong Y, Labarthe D, Mozaffarian D, Appel LJ, Van Horn L, et al. Defining and setting National Goals for cardiovascular Health promotion and disease reduction: the American Heart Association's strategic impact goal through 2020 and beyond. Circulation. 2010;121(4): 586-613.

2. Ommerborn MJ, Blackshear CT, Hickson DMA, Griswold ME, Kwatra J, Djoussé $L$, et al. Ideal cardiovascular Health and incident cardiovascular events: the Jackson heart study. Am J Prev Med [Internet]. 2016;51(4):502-6. Available from. https://doi.org/10.1016/j.amepre.2016.07.003. 
3. Foraker RE, Abdel-Rasoul M, Kuller LH, Jackson RD, Van Horn L, Seguin RA, et al. Cardiovascular Health and incident cardiovascular disease and Cancer: the Women's Health initiative. Am J Prev Med [Internet] 2016;50(2):236-240. Available from: https://doi.org/10.1016/j.amepre.2015.07.039

4. O'Neil A, Scovelle AJ, Milner AJ, Kavanagh A. Gender/sex as a social determinant of cardiovascular risk. Circulation. 2018;137(8):854-64. https:// www.ahajournals.org/doi/10.1161/CIRCULATIONAHA.117.028595.

5. Regitz-Zagrosek V, Oertelt-Prigione S, Prescott E, Franconi F, Gerdts E, ForystLudwig A, et al. Gender in cardiovascular diseases: impact on clinical manifestations, management, and outcomes. Eur Heart J. 2016;37(1):24-34

6. Lloyd-Jones DM, Wilson PWF, Larson MG, Beiser A, Leip EP, D'Agostino RB, et al. Framingham risk score and prediction of lifetime risk for coronary heart disease. Am J Cardiol. 2004;94(1):20-4.

7. Vlassoff C. Gender differences in determinants and consequences of Health and illness. J Health Popul Nutr. 2007:25(1):47-61.

8. Heidari S, Babor TF, De Castro P, Tort S, Curno M. Sex and gender equity in research: rationale for the SAGER guidelines and recommended use. Res Integr Peer Rev [Internet]. 2016;1(1):2. Available from: https://researchintegrityjournal. biomedcentral.com/articles/10.1186/s41073-016-0007-6.

9. Ahonen TM, Kautiainen HJ, Keinänen-Kiukaanniemi SM, Kumpusalo EA, Vanhala MJ. Gender difference among smoking, adiponectin, and highsensitivity C-reactive protein. Am J Prev Med [Internet]. 2008;35(6):598-601. Available from. https://doi.org/10.1016/j.amepre.2008.09.011.

10. Walters V. The social context of Women's Health. BMC Womens Health [Internet]. 2004;4(1):S2. https://bmcwomenshealth.biomedcentral.com/ articles/10.1186/1472-6874-4-S1-S2.

11. Perl $L$, Peiffer $V$, Fuhrer $A E$, D'Ascenzo F, Pietzsch JB. Sex differences in discharge destination following acute myocardial infarction. Coron Artery Dis. 2018;29(6):502-10.

12. Magodoro IM, Esterhuizen TM, Chivese T. A cross-sectional, facility based study of comorbid non-communicable diseases among adults living with HIV infection in Zimbabwe. BMC Res Notes. 2016;9(1).

13. Keates AK, Mocumbi AO, Ntsekhe M, Sliwa K, Stewart S. Cardiovascular disease in Africa: epidemiological profile and challenges. Nat Rev Cardio [Internet]. 2017;14(5):273-293. Available from: https://doi.org/10.1038/ nrcardio.2017.19

14. Mensah GA, Sampson UK, Roth GA, Forouzanfar MH, Naghavi M, Murray CJ, Moran AE, Feigin VL. Mortality from cardiovascular diseases in sub-Saharan Africa, 1990-2013: a systematic analysis of data from the Global Burden of Disease Study 2013. Cardiovascular journal of Africa. 2015;26(2 H3Africa Suppl):S6. http://www.cvja.co.za/onlinejournal/vol26/vol26_issue2_ supplement/files/assets/basic-html/page-8.html.

15. Tsai AC, Bangsberg DR, Emenyonu N, Senkungu JK, Martin JN, Weiser SD. The social context of food insecurity among persons living with HIV/AIDS in rural Uganda. Soc Sci Med [Internet]. 2011;73(12):1717-24. Available from. https://doi.org/10.1016/j.socscimed.2011.09.026.

16. Filmer D, Pritchett LH. Estimating wealth effects without expenditure data-or tears: an application to educational enrollments in states of India. Demography. 2001;38(1):115-32. https://link.springer.com/article/10. 1353\%2Fdem.2001.0003.

17. Craig CLC, Marshall AL, Sjostrom M, Sj??str??m M, Bauman AE, Booth ML, et al. International physical activity questionnaire: 12 country reliability and validity. Med Sci Sport Exerc 2003;35(August):1-7.

18. Riley L, Guthold R, Cowan M, Savin S, Bhatti L, Armstrong T, et al. The World Health Organization STEPwise approach to noncommunicable disease riskfactor surveillance: methods, challenges, and opportunities. Am J Public Health. 2016;106(1):74-8.

19. Rohde LE, Hennekens CH, Ridker PM. Survey of C-reactive protein and cardiovascular risk factors in apparently healthy men. Am J Cardiol. 1999; 84(9):1018-22. https://www.ajconline.org/article/S0002-9149(99)00491-9/ fulltext.

20. American Diabetes Association. Classification and diagnosis of diabetes: standards of medical care in diabetes-2018. Diabetes care. 2018; 41(Supplement 1):S13-S27. http://care.diabetesjournals.org/content/41/ Supplement_1/S13.

21. Salazar J, Martínez MS, Chávez M, Toledo A, Añez R, Torres Y, Apruzzese V, Silva C, Rojas J, Bermúdez V. C-reactive protein: clinical and epidemiological perspectives. Cardiology research and practice; 2014. https://www.hindawi. com/journals/crp/2014/605810/.

22. Feinstein MJ, Kim JH, Bibangambah P, Sentongo R, Martin JN, Tsai AC, Bangsberg DR, Hemphill L, Triant VA, Boum Y, Hunt PW. Ideal cardiovascular
Health and carotid atherosclerosis in a mixed cohort of HIV-infected and uninfected Ugandans. AIDS Res Hum Retrovir [Internet]. 2017;33(1):49-56. https://www.liebertpub.com/doi/10.1089/aid.2016.0104.

23. Hernán MA, Robins JM. Estimating causal effects from epidemiological data. J Epidemiol Community Health. 2006;60(7):578-86.

24. Williams R. Using the margins command to estimate and interpret adjusted predictions and marginal effects. Stata J. 2012;12(2):308-31.

25. Bambs C, Kip KE, Dinga A, Mulukutla SR, Aiyer AN, Reis SE. Low prevalence of ideal cardiovascular Health in a community-based population: the heart strategies concentrating on risk evaluation (heart SCORE) study. Circulation. 2011;123(8):850-7.

26. Wu S, Huang Z, Yang $X$, Zhou Y, Wang A, Chen $L$, et al. Prevalence of ideal cardiovascular Health and its relationship with the 4-year cardiovascular events in a northern Chinese Industrial City. Circ Cardiovasc Qual Outcomes. 2012;5(4):487-93.

27. Chang Y, Guo X, Chen Y, Guo L, Li Z, Yu S, et al. Prevalence and metrics distribution of ideal cardiovascular Health: a population-based, crosssectional study in rural China. Hear Lung Circ [Internet]. 2016;25(10):982-92. Available from. https://doi.org/10.1016/j.hlc.2016.02.007.

28. Haffner SM. The metabolic syndrome: inflammation, diabetes mellitus, and cardiovascular disease. Am J Cardiol. 2006:97(2 SUPPL. 1).

29. Abramson JL, Vaccarino V. Relationship between physical activity and inflammation among apparently healthy middle-aged and older US adults. Arch Intern Med. 2002;162(11):1286-92.

30. Kasapis C, Thompson PD. The effects of physical activity on serum Creactive protein and inflammatory markers: a systematic review. J Am Coll Cardiol [Internet]. 2005:45(10):1563-9. Available from. https://doi.org/10. 1016/j.jacc.2004.12.077.

31. Galland L. Diet and inflammation. Nutr Clin Pract. 2010;25(6):634-40.

32. Muyanja D, Allen JG, Vallarino J, Valeri L, Kakuhikire B, Bangsberg DR, et al. Kerosene lighting contributes to household air pollution in rural Uganda. Indoor Air. 2017;27(5):1022-9.

33. Olopade CO, Frank E, Bartlett E, Alexander D, Dutta A, Ibigbami T, et al. Effect of a clean stove intervention on inflammatory biomarkers in pregnant women in Ibadan, Nigeria: a randomized controlled study. Environ Int [Internet]. 2017; 98:181-190. Available from: https://doi.org/10.1016/j.envint.2016.11.004

34. Neupane M, Basnyat B, Fischer R, Froeschl G, Wolbers M, Rehfuess EA. Sustained use of biogas fuel and blood pressure among women in rural Nepal. Environ Res [Internet]. 2015;136:343-51. Available from. https://doi. org/10.1016/j.envres.2014.10.031.

35. Dutta A, Ray MR, Banerjee A. Systemic inflammatory changes and increased oxidative stress in rural Indian women cooking with biomass fuels. Toxicol Appl Pharmacol [Internet]. 2012;261(3):255-62. Available from. https://doi. org/10.1016/j.taap.2012.04.004.

36. Dutta A, Mukherjee B, Das D, Banerjee A, Ray MR. Hypertension with elevated levels of oxidized low-density lipoprotein and anticardiolipin antibody in the circulation of premenopausal Indian women chronically exposed to biomass smoke during cooking. Indoor air. 2011;21(2):165-76. https://onlinelibrary.wiley.com/doi/abs/10.1111/j.1600-0668.2010.00694.x.

37. Venkataraman C, Sagar AD, Habib G, Lam N, Smith KR. The Indian national initiative for advanced biomass cookstoves: the benefits of clean combustion. Energy Sustain Dev. 2010;14(2):63-72. https://www. sciencedirect.com/science/article/pii/S0973082610000219?via\%3Dihub.

38. Ogunmoroti O, Utuama O, Spatz ES, Rouseff M, Parris D, Das S, et al. Trends in ideal cardiovascular Health metrics among employees of a large healthcare organization (from the Baptist Health South Florida employee study). Am J Cardiol. 2016;117(5):787-93.

39. Moghaddam MM, Mohebi R, Hosseini F, Lotfaliany M, Azizi F, Saadat N, et al. Distribution of ideal cardiovascular Health in a community-based cohort of Middle East population. Ann Saudi Med. 2014;34(2):134-42.

40. National Center for Health Statistics US, 2010. Health, United States, 2009: With special feature on medical technology. https://www.cdc.gov/nchs/ data/hus/hus09.pdf

41. Vissandjee B, Desmeules M, Cao Z, Abdool S. Integrating socio-economic determinants of Canadian Women's Health. BMC Womens Health. 2004; 4(Suppl 1):S34.

42. Riha J, Karabarinde A, Ssenyomo G, Allender S, Asiki G, Kamali A, et al. Urbanicity and lifestyle risk factors for Cardiometabolic diseases in rural Uganda: a cross-sectional study. PLoS Med. 2014;11(7).

43. Liburd LC, Jack L, Williams S, Tucker P. Intervening on the social determinants of cardiovascular disease and diabetes. Am J Prev Med. 2005; 29(5 SUPPL. 1):18-24. 